\title{
IMPLICATIONS OF FEYERABEND'S ANARCHISTIC PHILOSOPHY FOR NIGERIAN EDUCATIONAL POLICIES
}

\author{
Samuel Aloysius Ekanem $\bowtie$; Department of Philosophy, University of Calabar, Nigeria \\ Peter Bisong Bisong; Department of Philosophy, University of Calabar, Nigeria
}

\begin{abstract}
Education is a very important variable of economic growth and development. It could be said that the rate of growth of an economy is directly proportional to the quality of education meted on the populace. This is the reason every society strives to educate its citizens. However, Nigeria remains backward in terms of education delivery. There are millions of unemployable graduates rooming her str eets searching for jobs. Though many reasons could be pointed as the cause of this, this work beams its searchlight on policymaking and implementation. It argues that if the right policies are made and dutifully implemented, the quality of education would improve. Using the tool of Feyerabend's anarchism, the work analysed the Nigerian Policy of education, pointing at areas of weaknesses and recommending action points for government and policymakers. It concludes that if Feyerabend's anarchism is made to guide policy-making in Nigeria, educational progress would ensue.
\end{abstract}

Keywords: Anarchism, Education, Policymaking, Nigeria, Educational Problems .

$\triangle$ samekanem2018@gmail.com

Citation: Ekanem, S. A. \& Bisong, P. B . (202 1). Implications of feyerabend's anarchistic philosophy for nigerian educational policies. Social Sciences, Humanities and Education Journal (SHE Journal), 2(1), 13 - 28. DOI: 10.25273/she.v2i1.8547

\section{(cc) BY-NC-SA}

Published by Universitas PGRI Madiun. This work is licensed under the Creative Commons AttributionNonCommercial-ShareAlike 4.0 International License. 


\section{INTRODUCTION}

Education is derived from "the Latin word 'educare', which means 'to draw out', or 'to unfold'. Thus, etymologically education could be said to be the process of releasing the latent potential that was dormant in an individual" (Ikegbu \& Bisong, 2015, p. 258). Education could be both informal or formal. This paper focuses on formal education, which is the education got from schools (Bisong 2020). Every culture in history has always had some level of interest in education. This is because of the immense benefit of education to an individual and the nation at large. Education is perceived as a means to sustain the social existence of individuals (Odey et al., 2019; Agbii et al., 2019). It also promotes national unity and integration, as well as ensuring the full independence and sovereignty of a country. A country cannot truly be developed if its educational sector is not well-developed. A country that seeks development does so in vain if it ignores education.

Nigeria like other developing countries is striving for development. Unfortunately, her educational sector is still crawling. Many who can afford it now send their wards to study abroad, leaving the no so rich to wade through the Nigerian schools. Though, it is noteworthy that attempts have been made over the years to reposition the Nigerian educational sector. It is sad to note, that these attempts have yielded little or nothing for the educational sector, as the quality of graduates produced yearly is continually nosediving. Most of these graduates could be described as educated illiterates. Bisong (2018) summarized it all, when he asserted: "the dearth of quality is clearly revealed by the fact that of the over 200 universities in Nigeria, only one is among the top 50 universities in Africa, and none is among the top 1400 universities in the world".

This research is out to help ameliorate this problem. It argues that policymaking and implementation is the real bane of Nigerian education. These policies are moribund and do not lead to progress as envisioned by Feyerabend. Therefore, all educational problems in Nigeria, as captured below could be traced to policymaking and implementation.

\section{EDUCATIONAL PROBLEMS IN NIGERIA AND THE NEED FOR POLICIES SHIFT}

As has been shown already there are immense benefits accruable from a sound education in a country. Nigeria is struggling to tap the benefits of education due to a lot of factors. This subsection will therefore explore the important factors militating against a sound educational delivery in the country. The factors are:

Poor quality teachers: the importance of good quality teachers to qualitative educational delivery cannot be overemphasized (Hamzah et al., 2020). The Nigerian Policy on Education in recognition of this declares that no education can rise above the quality of its teachers (Nigeria 2004). Ukeje (1996) also supports this point, he believes that a programme of education for social regeneration or reconstruction cannot be merely transmitting content and relating it to the life of the people; it must also involve the assurance that such content is well transmitted to the learners. This means that the teachers who are in charge of effecting such instructions should be taken into consideration, for if the vision of the society must be attained, the teachers will need to be good. The students cannot on their own acquire the skills needed to fill in the manpower gaps in society unless the teachers who teach them have 
these skills (Agbii et al., 2018). Thus, we can say that the low quality of teachers in Nigeria is the reason why the country is crawling in terms of development.

The federal government of Nigeria in an attempt to raise the quality of teachers, prescribed the National Certificate in Education (NCE), to be the minimum qualification for all teachers in the primary and junior secondary schools (Nigeria Policy on Education). Before this time the minimum qualification for teachers within this category (primary and junior secondary school) was the Grade 11 certificate which was obtained in the Grade 11 Teacher College. The N.C.E is obtained from colleges of education (COE). There are currently about 83 of these institutions, enrolling about 500000 students and graduating more than 100000 a year, colleges of education were established to increase the supply of teachers as well as improve their quality. To ensure conformity in standards of curriculum and implementation, the National Commission for Colleges of Education (NCCE) was established to supervise, monitor and accredit COES.

The problem here is that the NCE programme from the beginning was not intended for the production of primary school teachers but for junior secondary schools. This means that prescribing the NCE for primary schools without adjusting or restructuring the curriculum of the COEs to fit into the requirement of primary education weakens the quality of teachers for primary education. To use a curriculum that is meant to train teachers for junior secondary education to train teachers for primary education will produce teachers who are illprepared to handle primary school students. Recently, however, Primary Education Studies (PES) has been introduced into the NCE curriculum as an option for students who intend to teach in primary schools, but even then, according to Ajeyalemi (2008, p. 26), less than $10 \%$ of students elect to choose PES.
As a consequence, there is a low level of qualified teachers with the appropriate NCE at the primary level of education in Nigeria; the majority of teachers at this level posse NCE appropriate for teaching at the junior secondary school level. This means that most teachers at this level are not qualified

In addition to this problem of quality and quantity in teachers for the primary level, only a few candidates apply to the COEs for admission compared to those applying to universities. Those who apply to the COEs are normally those who are not qualified for admission into university those who have less than five credit passes in the required subjects. This class of people reluctantly applies to COEs as the last option. This means that those who choose to be trained as teachers are either not good enough intellectually or are less motivated to teach since they choose teaching as a last resort and not as a first choice.

To add to this, the colleges are poorly funded leading to low-quality teaching and learning. The infrastructure and facilities are poor, making the training programme too theoretical; the duration of teaching practice is too short and the level of supervision inadequate. These problems lead to the production of teachers who are qualified in terms of certificates but who are not competent to teach at the intended level of education. The implication is that there is a shortage in supply of quality teachers at the basic education level (Ajeyalemi 2008, p. 28).

The problem of quality of teachers is not limited to basic education; even the senior secondary schools also suffer it. The universities are responsible for training teachers for this level of education according to the Nigerian Policy on Education. The Faculty of Education is established in the university for this purpose - the training of teachers for senior secondary education. However, as with the COEs, few candidates elect as the first choice to study education, the assigned quota for 
education by the National University Commission (NUC) is majorly composed of candidates who could not gain admission into lucrative courses like medicine and surgery, law, accounting, engineering, etc. This means that the not so good intellectually opt to be trained as teachers. How can Nigeria have quality teachers when those who get themselves trained are low-class brains who failed the intellectual competition for more lucrative courses?

As with COEs, the universities are not well funded leading to the production of incompetent teachers as recent studies have shown. It is believed that most of the graduates from the universities in the last 15 years are incompetent as teachers. They are not competent in the knowledge of the subject as well as in teaching and communication skills (Okebukola 2997). This implies that the acquisition of the Bachelor's Degree in Education does not necessarily make qualified teachers who are competent to teach at the senior secondary school level. Obanya et al (2004), for instance in a study found out that, secondary school teachers in four Nigerian states (Enugu, Kaduna, Lagos and Rivers), demonstrated poor quality teaching. Obanya also found shortfalls in the supply of teachers in the four states studied for almost all secondary school subjects, including the so-called soft ones like Religious Studies, Commerce, etc.

It could therefore be concluded from the above that the basic and postbasic education system in Nigeria lacks a good supply of quality teachers. Because of this low-quality education is meted out to the students, helping to compound the overall problem of education in Nigeria. Most students graduate from secondary schools knowing little, some come out without being able to read. These students are milled out into the universities without much preparation to receive a university education. In order to fit in, they cut corners, helping to degenerate the already fallen system of education. A change of policy on teacher training and selection is, therefore, necessary for better educational delivery.

Unstable staff: due to poor salary and condition of service of teachers in the country, people tend to use the teaching profession as a stepping stone to other more lucrative jobs. Those who take up teaching appointment sees this as a temporary arrangement until the dream jobs are gotten. In consequence, the teaching force in the Nigerian schools has always been in flux - constant movement out and in of teachers. It is mostly made up of fresh graduates who will quickly drop it when a better job is found. This is a great challenge to educational development in the country.

It is the length of time spent on a job that determines the experience of an individual. Since teachers are constantly moving out and in, it could be said that Nigerian schools lack experienced teachers, which implies that the quality of teaching is low. The importance of experience to quality performance is invaluable; this is why almost all recruitment exercises spell out experience as an added advantage. The instability of the teaching force deprives the schools of the experience needed to improve quality delivery. A policy that would make the teaching profession lucrative and attractive, thereby enabling the retention of teachers.

Poor educational funding: many schools in Nigeria have no enough supply of equipment and personnel to man them. The laboratories, libraries, workshops are ill-equip. The classrooms are overcrowded because there are not enough structures, making one teacher handle up to one hundred students (Adesina 1988). According to Bisong (2018), funding is the heart of education. This is because funding is needed for the various aspects of education, the planning, equipment, facilities, structures, teachers and other staff. Despite this known importance of funding to education, not much is done in Nigeria to improve the funding of 
education in the country. The minimum budgetary allocation requirement of $26 \%$ recommended by UNESCO for the educational sector in the developing countries has never been met by the Nigerian government. This according to Bisong (2018, p. 211) is the greatest challenge facing educational development in the country (2).

As a result of the underfunding of education, problems of poor infrastructure, low teaching and learning materials, inadequate workshop tools and facilities, dilapidated buildings, overpopulated classrooms and other issues persist in the educational sector of the country.

Access to education: equality of access to education is not yet achieved in Nigeria. Most children especially those from the poorest families, the landless, working children, children of migrant or pastoralist families, children of minority groups, orphans, children affected by HIV/AIDS and children with physical or mental challenges. In some parts of the country like the North, female children do not have equal access to education.

Getting access to institutions and courses of choice in Nigeria by candidates is still riddled with difficulties occasioned by tribalism, nepotism, ethnicity and such vices. The indigenenon indigene factor is restricting access to education for a lot of candidates. Most times it is the candidate with rich parents who are willing to pay that get the more lucrative courses like medicine and surgery, law, etc. Those who are poor get themselves shut out from these courses and being forced to study what they would not want to. Being forced to study a course outside one's choice makes the student unserious and thus unable to do well academically.

Most people especially in rural areas are not able to attend school because of the distance of the school from their places of abode. Of course, they will not be able to afford the transportation fare daily to school. Because of different parameters, therefore, access to education is posing a grief challenge to educational delivery in the country.

Inadequate and irrelevant curriculum: the Nigerian educational curriculum has been severely criticized by many scholars (cf Ukeje 1996; Fanfunwa 1982; Bisong \& Ekanem 2019). It is believed that the curriculum of Nigerian schools is too theoretical, with little practical and thus unable to adapt Nigerians to the ever-changing world of technology. UNESCO, therefore, believes that curricula need to be revised "if they are to prepare youngsters to live in a society marked by the explosion of new knowledge in science and technology by information and communication.

The problem of a selection process: Ukeje (1966, 107)) believes that the problem of the curriculum is less in magnitude and significance when compared to the effects of a rigorous selection process that tend to limit the opportunity of the great majority of the candidate seeking education. According to him, in a country like Nigeria which needs social reconstruction, the target of education should be on the majority. He argues that stringent selection as is done in Nigeria only produces a tiny minority who are likely to lead without much protest from the ignorant majority with the greater possibility of not maximally realising the group self. In Nigeria, millions apply for university education every year and the number admitted is not up to half of this number. He accuses the system of elimination which centres on examination as highly unreliable, for it is rarely employed as a diagnostic tool for improving teaching and learning but as an elimination device in addition to their lack of validity and limited sampling. This process of selection that leaves many out and letting in only a few has been a big problem to educational development in Nigeria. We wonder the rationale behind the many restrictions imposed in Nigeria against candidates seeking admission into universities. One 
has to write WAEC, then JAMB and then attitude test. A country like Nigeria that is so educationally backward should not drive away candidates who want to improve their education.

The problem of language: Most scholars acknowledge the effects of using an alien language to instruct students. Language constitutes an important component of every culture whose codes together define the limits of understanding; cognition is therefore hampered when a strange language is used as the vehicle of instruction. Apart from this, a double language system creates a dichotomy in the life of a child. A child is divided. Thus, education that is supposed to aid solve social problems becomes itself a problem when a foreign language is used as a medium of its conveyance. Due to this problem of language, the Nigerian child stands at a disadvantage when compared to his counterpart in America, Britain, France, China, etc where their mother tongue is the language of instruction in schools. This is why they are more equipped than the Nigerian child in tackling their societal problems.

Corruption: the fact that Nigeria is a corrupt nation is no longer news. In all spheres of the Nigerian economy, corruption is seen as rearing its ugly head. It has permeated the primary, secondary and tertiary levels of education. At all levels of the educational system in Nigeria cases of examination malpractice, sexual harassment, cultism, extortion, prostitution, stealing, compromising of standards and integrity, etc involving lecturers/teachers, students and other staff of schools abound. Also at the federal and state ministries of education, leaders are seen looting and laundering the monies meant for the development of education.

These problems and many more underscore the importance of good policymaking and implementation. The Nigerian policies regarding education, though well-meaning lack the capacity to reposition education in the country and thus must undergo quaking, which Feyerabend calls anarchism.

\section{AN OVERVIEW OF FEYERABEND'S ANARCHISTIC PHILOSOPHY}

Feyerabend attempted to tackle the general assumption that the success of science is because it proceeds through a strict methodological procedure. He was worried about the erroneous belief in the existence of a universal method. $\mathrm{He}$ denied the existence of one method of doing scientific research. Rather, he surmises that science proceeds by many methods, and he goes on to argue that all methods have their limitations. Hence, his approval of anarchistic methodologies and anarchistic science (1975, p. 21). He accepted the fact that standards emanate from the research process and not from an objectified abstract view of rationality as contained in an assumed universal method of science presented by Popper or Kuhn. He was not completely against standards but rigid conformity to a particular rule irrespective of the intervening variables in nature. In his words "... the attempt to discover the secrets of nature entails, therefore, the rejection of all universal standards and of all rigid tradition" (Against 20). To him, the scientist or epistemologist should approach his research dispassionately with an open mind to traditions of probing the complexities in nature. Feyerabend's research in quantum theory reveals that scientists seldom follow their laid down rules during research and that falsification of the rationalist was a pseudo solution to the scientific problems of methodologies. As a reaction to the Popperian methodological conventionalism, Feyerabend maintains that the rift between realists and instrumentalists is not a factual issue but a matter of choice. He argued further that theories can be seen as either description of reality or as instruments of prediction depending on the interest of scientific 
knowledge we aspire to. Feyerabend's defence of realism was predicated on the fact that the interpretation of scientific theory depends upon the states of affairs it describes. He takes this argument further in his work 'How to be a Good Empiricist' that scientific realism was methodological realism, highly desirable because of its disposition to the proliferation of new and incompatible theories which for him leads to scientific progress. Scientific progress can be attained through theoretical pluralism.

Before embarking on his intellectual defence of the anarchistic view of science, Feyerabend carefully identified the inherent contradictions and loopholes in the methodology of science put forward by the logical positivists, critical rationalists and Thomas Kuhn. In his carefully packaged critique Against Method, Feyerabend exhibited a complete shift from his flair for a pluralistic methodology to anarchism. He stated that the older theories like the Aristotelian theory of motion had strong empirical and argumentative support while maintaining that the heroes of the scientific revolution like Galileo were not carefully conducted as they were sometimes portrayed to be. He stressed that Galileo used all manner of gambit and epistemological make beliefs to advance his theory of heliocentrism. He further downgraded the importance of empirical argument by indicating that social factors have a far more decisive role in the history of science than the rationalist's position would indicate. $\mathrm{He}$ implied that logical empiricist methodologies and Popper's critical Rationalism will inhibit scientific inquiry by enforcing restrictions on new theories.

Feyerabend draws on the anarchist conclusion that there are no useful and exceptional methodological rules governing the progress of science or the growth of knowledge. $\mathrm{He}$ acknowledged that though Lakatosian methodology was a bit sophisticated, it contains ungrounded value judgment about what constituted a good science, hence its reasonability is only because it is epistemological anarchism in discourse. However, Lakatus could not escape his sensist. He criticizes Lakatos because he vilifies science against other disciplines like magic or myth. He maintains that science is only one ideology among several other ideologies. Feyerabend is of the view that science is but one ideology among many. His contention here is that the defenders of science judge it to be superior to other forms of knowledge without adequately investigating those other forms of knowledge. Those such as myth, magic, faith-healing with hand, religion and voodoo.

Feyerabend advanced strong arguments against science privileged position within culture. For him, science seems to have prevailed because science is enjoying the patronage of the state for many obvious reasons some of which are the benefits of the results of science to the political, social and economic advantage of the society. He admits that science is much closer to myth than a scientific philosophy is prepared to admit. It is one of the many forms of thought that have been developed by man, and not necessarily the best. It is conspicuous noisy and impudent, but it is inherently superior only for those who have already decided in favour of a certain ideology or who have accepted it without ever having examined its advantages and its limit (science and myth295). It is in this line of argument that Feyerabend believes that the reasons that led to the separation of religion from the state can also be put forward for the separation of science from the state. Against the background, people would be at liberty to choose freely the belief systems that should guide their lives. He believed that science is a threat to democracy. He cited an example of the American society which imposes the teaching of science as the compulsory subject but religion is 
optional. Feyerabend's concern here is that the critical abilities are annulled as the child sees the world as a place of already formed ideas with the specific social and informed context within which he shall do his living and learning. In this regard, Feyerabend believes that science has now become an oppressive ideology like the once upon a time judgement of the Bishops and Cardinals of the church to Defend Society against Science (159).

Feyerabend is not outrightly undermining science in its totality but rather he is concern about the seeming dangers associated with the tyranny of science over other forms of knowledge. Feyerabend worry is not farfetched because, in our contemporary society where morality has been subjected to the inclination of relativism, we are faced with the dangers of annihilation with the advancement in biotechnology and other aspects of science threatening our humanity. Feyerabend's anarchism has been criticized by various scholars. It is argued that, a society where "anything goes" the principle that will be at work is "everything stays". Besides, his comparison of science with myth, voodoo, witchcraft, astrology and the likes has been regarded as unholy (Uduigwomen 2009, p. 118).

But it seems to me that these attacks on Feyerabend arose from the misconception of his usage of the term anarchism and the phrase anything goes. In his book Science in a Free Society entitled conversations, with illiterates. He berated his readers and reviewers for having misread his method. Feyerabend states clearly that his motives for writing against method were to free people from the tyranny of philosophical obfuscators and abstract concepts such as "truth", "reality" or "objectivity", which narrow people's vision and ways of being in the world (1975, p. 80). On the other hand, if we consider anarchism from its etymology "an archos" meaning without a head or chief or without a top authority", then his critiques could have been right but the epistemological impart of Feyerabend's choice of anarchism purports decentralization. To Feyerabend, however, anarchism would be applied to epistemology and the philosophy of science only as a medicine to cure the problems that hinder the growth of scientific knowledge.

\section{THE IMPLICATION OF FEYERABEND'S ANARCHISM TO THE NIGERIAN POLICY OF EDUCATION}

Going by Feyerabend's anarchistic method, policymaking will cease to be an activity that proceeds from above to below. It will cease to be solely a vertical moving activity but an activity that is at once horizontal and vertical. This means that the subordinates, that is, the teachers as well as the students are expected to partake in educational policy-making. It is not a thing that is enacted or formulated above and imposed on the teachers and students. The participants of the policymaking must embrace the teachers, the students and other stakeholders like the church, the traditional ruler's council, trade unions, etc. This corresponds to what Dennis Lloyd (1975) wrote regarding laws, he asserts:

The law is a great social fabric constituted by human behaviour in all the mass of transactions which have legal significance ... in our own day when the worldwide spread of Western ideas and technology has brought to light so many ideological conflicts and created many more new ones, it is not difficult to grasp the fact that law which is after all one of man's main social artifacts is inevitably deeply embedded in the ideologies of the society in which it operates $(215,219)$.

Policies, as well as laws, are social fabrics that must get their legitimacy from society. They cannot exist outside the society and therefore should not be 
contrived devoid of societal influence. This corroborates Asouzu dictum which says "anything that exist serves a missing link within the framework of the totality (1990, p. 83). Missing link according to him is the "mode through which being can be grasped within any given framework of finite determinism, as it can only be grasped through relations" (2007, p. 266). He believes that for anything to claim existence, it must exist in a complementary relationship with other missing links (Bisong 2015, p. 13). This means that for a policy to claim existence and have significance, it must exist in a complementary relationship with other social institutions. Any law that divorce itself from this complementary relationship ceases to be law. For nothing can exist in isolation and claim meaningful existence. No policy, therefore, is isolated from the society, it tugs on the society and the society in turn influences it. This means that an educational policy should accommodate inputs from other social institutions for it to be effective. Any educational policy that does not follow this format runs the risk of being devoid of life.

Since laws and policies derived are aimed at the betterment of society, they must aim at solving the myriad of problems of the society. Thus, educational policies following the dictates of anarchism must not follow the caprices of the rulers but aim at solving perceivable problems in the educational sector. Nigeria has a lot of educational problems, from low-quality teachers to poor infrastructure and corruption. Education policies should be aimed at tackling these issues to enable progress to ensue in the sector.

Also, since the educational needs of the society are not constant but keep on evolving, it means educational policy needs to continually evolve along with the changing needs in the educational sector (Aboh, 2016; Umukoro 2016; Aboh, 2016). When policies aimed at solving problem 'A' still remain even when problem ' $A$ ' has changed to problem ' $\mathrm{B}$ ' there become moribund and devoid of virility. This is because policies that are effective in tackling problem ' $A$ ' may not be effective in tackling problem ' $B$ '. This is why Ndifon (2002) asserts succinctly that "law cannot be divorced from the goings-on in the political, social and economic spheres ... laws are based on identifiable social problems (287, 289). The educational policies and laws must be geared towards solving the problem of poor quality and quantity of teachers, examination malpractice, sexual harassment, buying and selling of grades, ethnicity, godfatherism, corruption, low infrastructure, low remuneration of teachers and other staff, constant strikes and other problems that bedevil the Nigerian educational system. At present, the educational policy of Nigeria favours science over other subjects. This is strongly kicked against by Feyerabend in his work 'Science and Myth". He contends:

And yet science has no greater authority than any other form of life. Its aims are certainly not more important than are the aims that guide the lives in a religious community or in a tribe that is united by a myth. At any rate, they have no business restricting the lives, the thoughts, the education of the members of a free society where everyone should have a chance to make up his own mind and to live in accordance with the social beliefs he finds most acceptable. The separation between state and church must therefore be complemented by the separation between state and science (http://www.inf.fuberlin.de/lehre/pmo/eng/Feyera bend-ScienceMyth.pdf).

Most scholars in Nigeria have argued for higher attention to be given to science education than arts education. Jibril Aminu (1986) for instance favours a science/art ratio of 60: 40 in 
admissions to universities and 70: 30 for Polytechnics and 80: 20 for Universities of Technology (314). These yearnings by Nigerian scholars seem to have been embraced by Nigeria. Today, science occupies a pride of place in the country. The scholarship is given more easily and readily to science students than the art students; the science students are given more admission quota than the art students, remedial programmes which are solely for science courses make it easier to get admission into science courses than art courses. According to Feyerabend:

The reason for this special treatment of science is, of course, our little fairy-tale, $p$. if science has found a method that turns ideologically contaminated ideas into true and useful theories, then it is indeed not mere ideology, but an objective measure of all ideologies. It is then not subjected to the demand for a separation between state and ideology (1975, p. 116).

Feyerabend contends further:

But the fairy-tale is false ... There is no special method that guarantees success or makes it probable. Scientists do not solve problems because they possess a magic wand - methodology, or a theory of rationality - but because they have studied a problem for a long time. After all, they know the situation fairly well, because they are not too dumb (though that is rather doubtful nowadays when almost anyone can become a scientist), and because the excesses of one scientific school are almost always balanced by the excesses of some other school. (Besides, scientists only rarely solve their problems, they make lots of mistakes, and many of their solutions are quite useless.) There. is hardly any difference between the process that leads to the announcement of a new scientific law and the process preceding passage of a new law in society: one informs either all citizens or those immediately concerned, one collects 'facts' and prejudices, one discusses the matter, and one finally votes. But while a democracy makes some effort to explain the process so that everyone can understand it, scientists either conceal it, or bend it, to make it fit their sectarian interests (1975, p. 116).

Considering this observation by Feyerabend, we can say that overemphasis on science is detrimental to the advancement of knowledge. If we want to know and understand nature; if we want to master our natural or physical environment, then we must use all ideas, all methods, and not just a few of them. Thus, the Nigerian policy of education should be such that all subjects are given equal attention and opportunities (Dennis 2020). The Arts and Humanities are not less important than the natural sciences. The few accolades Nigerians have received over the years almost entirely come from the Arts and Humanities - Wole Soyinka and Chinua Achebe are good examples of products of Arts that have brought honours to the country. This shows that Arts and the Humanities can lift Nigeria and include it among the comity of nations if properly developed alongside the sciences. All disciplines must be given a fair chance to develop. In the years past Nigeria's juju priests and herbalists have served the people so well and should be given the chance to develop alongside Western education. We believe in this work that if given the chance to develop this locked up knowledge may shock the world and even science itself. In Ogep, a village in Cross River State, a juju priest when treating a fractured leg or hand will not make physical contact with the leg or hand. He will only break the leg of a fowl 
or cockerel, depending on whether the person is a female or male and treat it. When the leg of the fowl or the cockerel heals, the patient too will get well. Surely, knowledge of this kind will astound science and the world in general if allowed to develop in our schools. Nigerian policy on education should make it possible for such knowledge and other hidden and dying knowledge to be brought up and improved upon in schools. This will allow the students to get the knowledge of their forefathers and possibly the world will come to the feet of Nigerians to also learn from them. Nigeria will also need to teach something to the world and thus should not hide and consider its knowledge as inferior but as equal in status to other forms and bodies of knowledge. This traditional knowledge, therefore, needs not to be thrown away for there are still very useful. Feyerabend comments on the usefulness and achievement and the capacity of traditional knowledge to compete favourably with modern science in these words:

Primitive tribes have more detailed classifications of animals and plants than contemporary scientific zoology and botany, they know remedies whose effectiveness astounds physicians (while the pharmaceutical industry already smells here a new source of income), they have means of influencing their fellow men which science for a long time regarded as non-existent (Voodoo), they solve difficult problems in ways which are still not quite understood (building of the pyramids; Polynesian travels), there existed a highly developed and internationally known astronomy in the old Stone Age, this astronomy was factually adequate as well as emotionally satisfying, it solved both physical and social problems (one cannot say the same about modern astronomy) and it was tested in very simple and ingenious ways (stone observatories in England and in the South Pacific; astronomical schools in Polynesia ... There was the domestication of animals, the invention of rotating agriculture, new types of plants were bred and kept pure by careful avoidance of cross fertilisation, we have chemical inventions, we have a most amazing art that can compare with the best achievements of the present. True, there were no collective excursions to the moon, but single individuals, disregarding great dangers to their soul and their sanity, rose from sphere to sphere to sphere until they finally faced God himself in all His splendour while others changed into animals and back into humans again. At all times man approached his surroundings $\mathrm{w}^{\prime} \mathrm{h}$ wide open senses and a fertile intelligence, at all times he made incredible discoveries, at all times we can learn from his ideas (http: //web.mit.edu/sdmorr/Public/ST S/feyerabend.pdf).

It is, therefore, the belief of this researcher that if the educational policy is made to favour our traditional knowledge, knowledge will progress faster than this. Feyerabend's anarchism being a philosophy that is against standard rules will invariably be against standard rules of teaching and assessment of students. It will favour different teaching methods and not a specific one. Applying Feyerabend's philosophy therefore to the Nigerian system of education will mean that Nigeria will need to evolve and employ different teaching methods for her students. There are different teaching methods, which include:

Teacher centred method. This method is often called the closed-ended method because it involves little or no 
participation of the students. Here the teacher poses as an expert and a master of the subject and pours in the content of his knowledge to the students who are passive listeners.

Student centred method. In this method, the students are allowed to take active participation in class. the teacher here does not assume the position of a master of the subject - he sees himself as both a teacher and a learner (Hamzah 2020).

Content centred method. This method subordinates the interest of the teacher and the students to the content of the discussion. The content is held sacrosanct and all discussions are based on that.

\section{Interactive/participative}

method. This method borrows from the above three without necessarily emphasizing any of them. That is, it cuts across the three domains.

Other specific methods of teaching include: the lecture method, the discussion method, the demonstrative method, the buzz group method, brainstorming method, role-play method, the study assignment method, the tutorial method, the seminar method, the case study method, panel of experts method, et cetera.

The method that is prominent in the Nigerian system of education is the teacher centred method, which sees the students as empty drums that need to be filled to the brink with the knowledge that is solely in the teacher. The teacher sees himself/herself as the boss and dictates the tune of the class for all to follow obediently to avoid being punished (Yunus 2020). This method makes students passive receivers of education and thereby encouraging passiveness in students. This is against Feyerabend'sFeyerabend's idea of anything goes. Passive students are hardly creative and are likely to follow standards passively and sheepishly when this happens the standards will be worship and will not be overthrown for progress to be ushered in. The banking method or the teacher-centred method of education will encourage and psychologically build in the students, blind obedience or allegiance to authority. Feyerabend's idea of education is one that will raise critically minded students who will subject everything to questioning and analysis and not blindly accepting acclaimed facts.

Anarchism as envisaged by Feyerabend will want all the methods of teaching to be adopted by teachers. This we believe in this work as a right, because one student may not do so well academically in one method but learn better in another. Feyerabend in his work 'Science, $p$. The Myth and its role in society' comments on this thus, p. "Modern science, on the other hand, is not at all as difficult and as perfect as scientific propaganda wants us to believe. A subject such as medicine, or physics, or biology appears difficult only because it is taught badly, because the standard instructions are full of redundant material, and because they start too late in life" (http: //web.mit.edu/sdmorr/Public/STS/fey erabend.pdf ). Yunus (2020) also questions educational activities based on a unique pedagogical model, which would certainly be appropriate for some, but ineffective or less effective for the other group members. The use of a plurality of methods, he believes will make the school more attractive to most students.

This work advocates for multiple teaching strategies such as encouraging reading, generating conflicts based on empirical and conceptual contradictions at various levels, creating problem situations, discussions sessions with arguments grounded in theories, development of concept maps, seminars, exhibits, laboratory classes, questioning, among other widely used methods, should be employed in teaching. The teaching tools and methods should be employed in the search for better understanding and teaching. The teacher 
should adopt pedagogical pluralism (multiple teaching methods), which means he has to constantly examine the proposals made by researchers for teaching, innovating, taking risks and experimenting in his classroom. Adopting pedagogical pluralism will carry different students from different backgrounds and orientations along. If method 'A' does not go well with student 'S', it will mean student ' $S$ ' will not do well in a class if this method is made the sole method of teaching. To carry all students along, varied methods of teaching must be employed, so that if this method does not fit one student another may fit him. Thus teaching should be teachercentered as well as child-centre, demonstrative as well discursive, theoretical as well as practical et cetera.

In the same vein, assessment should not follow one method as is the case in Nigerian schools where only written examinations are prominent as an assessment method. In written examination, a student who cannot write fast, or who has bad and illegible handwriting or who is not just good in writing will be judged unintelligent by the assessor due to the scores he is likely to get. They are students who talk better than they write. For such students employing just written examinations as assessment tools will not be fair. On the other hand, too, they are students who write better than they speak. This will be favoured by written examination, for they are going to excel better than the former category of students. In another sense, some students do better when they have enough time to think about a particular problem. Such students will do poorly when constraint to solve problems within a very short time. However, some other students are sharp and can unravel problems and solve issues very fast, such students will definitely do better than the former in examinations where there is a limited time. Is the fast thinker more intelligent than the slow thinker? This is a question that must be answered by an educationist. In this work, we think the answer is no. The student who needs more time to get to the answer is not less intelligent than the one that needs little time. Thus not being able to give a reasonable answer to an impromptu question does not make me an unintelligent person. There is also a category of a student who may be intelligent but has difficulties with language; there are a lot of intelligent students who have problems with communicating their knowledge to the outside world. This set of people will be judged unfairly in examinations that involve writing and oral. They will score low in such exams because of their inability to communicate their knowledge. It is for these differences in humans that we think that the anarchistic philosophy of Feyerabend will do well in education if employed as an underlying philosophy of education. Anarchism will not favour a straightjacket method of assessing students. It will rather favour a variety of methods. The method that favours one person may not favour another. However, when different methods have been employed the method that does not favour one person will favour another, and the one that is not favoured by this will be favoured by the next and in the end, all will be treated fairly. Those that are good in writing will be examined through written examination; the ones that are good in talking will be examined by oral examination, the ones that are not good in examinations due to examination fever or due to their inability to think fast under a limited time could be tested through assignment and seminars and those who have communication problems like English could be examined in their indigenous languages. This means the assessment method must be made to suit the child and not the other way round as is the case in the Nigerian schools.

All these points to the fact that a teacher that will fit Feyerabendian anarchistic conception has to be well 
trained and must be vast. This is contrary to the Nigerian situation where teachers are poorly trained and are unqualified to teach. The teacher training curriculum does not include subjects that will inculcate the multiple teaching methods in the would-be teachers. It is a curriculum that breeds teachers who become lords and masters in class while the students are made empty vessels that need infilling from the teachers. The student teachers' curriculum needs to be expanded to include the various teaching methods to be used in class. It has also to include the various assessment methods to be used to grade students. When these are included in the curriculum and the student teachers made to pass through them that is, the moment teachers will be well equipped to teach appropriately.

In Nigeria, the teaching profession is seen as a temporary job for fresh graduates who see the teaching job as a place holder for better jobs. They hold on to teaching to make ends meet with the hope that a better job will come in the future, and immediately after this job comes they abandon teaching. The education policymakers need to ensure there is adequate retention of good teachers, by increasing the remuneration and working conditions of teachers. Teachers are not less important than other professionals in Nigeria and thus should not be treated as such. Feyerabend quarrels with the elevation of science to a superior cadre above other disciplines; he will also quarrel with the elevation of other professions above the teaching profession in Nigeria. No profession could claim superiority over the other and therefore all should be given equal opportunities to grow. This implies that the teaching profession following the Feyerabendian idea of anything goes will need to be ranked at par with the so-called best professions like engineers, medical doctors, oil workers. Politicians etc - should be given similar attention and care as these other professions receive. When this is done, that is the moment a lot of intellectuals will desire to be teachers and will willingly enroll into the university to study education in order to become a teacher. At present students who find themselves studying education are mostly those that failed to get admission into the so-called prestigious courses. Nigerian students normally eye Law, Medicine and Surgery, Engineering, Accounting, etc, when they fail to meet up the cut-off point for these courses, they reluctantly choose or are forced into educational courses. The resultant effect is that the brightest students who meet the cut-off points for these well sought after courses go for these courses, leaving the no so brilliant to study education. if those who study education (that is the future teachers) are not the best of brains, then we can imagine the kind of quality of teachers we will have. The best brains will continue to go for these prestigious courses and the dullest brains to education, if the policymakers do not make it in such a way that, the teaching profession competes in attractiveness with other professions. Going by the Feyerabendian dictum that conceives no course to be superior to the other, the Nigerian educational policymaker needs to make policies that will elevate the teaching profession to equal the standards of other professions, if there must be progress in the Nigerian educational system.

\section{CONCLUSION}

This work concludes that Feyerabend's peculiar conception of anarchism needs to be made the underlying philosophy of the Nigerian educational system. The Feyerabendian system needs to serve as the foundation upon which the Nigerian educational system is built. That is, Nigeria needs to rebuild its educational system on a foundation constructed by the anarchistic philosophy of Feyerabend. This implies that the teaching methods will need to be diversified to meet the different needs of the students. Since the 
students are from diverse cultures, have different experiences, come from different orientations and carry different ideologies, the method of teaching will need to be constructed in such a way that all of the students will be accommodated. This means that the teacher education curriculum will also need to shift to inculcate different teaching skills in the teachers. The current assessment method by written examination will also need to be overhauled to give way to multiple assessment methods. The written examination will no more be the sole means of assessing the students. Students will need to be given the freedom to choose how they want to be examined.

Anarchism will also imply that educational policymaking will no longer be fixed and absolute rather it will be flexible and relative. Since policies are meant to solve problems and educational problems are continually changing, the policies must also change along with the problems. Feyerabend anarchism also implies that educational policymaking must be such that allows all subjects equal educational status. The policy should be such that one will be given the freedom to choose any course of study he wishes, just like one is free to choose any religion of his choice. One could choose to study magic or myth and should be allowed and supported to do so. These courses must be included in the curriculum and made available for students to study if they so choose. Also very importantly this work avers that the Nigerian education policy should be such that will enhance the students and not limit them. It should not be restrictive but liberating. This means that the various restrictions like WAEC, JAMB and university attitude tests place on the way of the university candidate need to be weakened to allow greater access to higher education. JAMB and attitude tests are playing no noticeable useful positive function but a negative one of inhibition of the efforts and desire of the pupil to receive higher education. When these hurdles on the way of the intending students are removed, this researcher believes that a better educational system will ensue. As many Nigerians will get a chance to get educated which will invariable improve their productivity and by extension improve the general productivity of the country, thereby leading to economic growth and development.

In conclusion, this research believes that Feyerabend's anarchistic philosophy has the potential of bringing progress to the Nigerian system of education and thereby placing it among the best educational systems in the world.

\section{REFERENCES}

Aboh, J. A. (2014). Conflict management: A panacea to development. Sophia: An African Journal of Philosophy, 14(2), 64-67.

Aboh, J. A. (2015). Assassinating political opposition: An" Albatross" and aberration-the Cross River example. Sophia: An African Journal of Philosophy, 16(1), 211215.

Aboh, J. A. (2015). Child labour and forced marriage: Modern slavery in Nigeria. Sophia: An African Journal of Philosophy, 15(2), 15-19.

Aboh, J. A. (2016). Decolonization of Africa as an illusion and as a noble dream: the case of Nigeria. Lwati: A Journal of Contemporary Research, 13(2), 17-27.

Adesina, S. (1988). The Development of Modern Education in Nigeria. Ibadan: Heinemann Educational Books, 1988.

Agbii, S. U., Chukwu, C. E., \& Iwundu, N. (2018). Perceived Influence of Human Capital Development on Teachers in the Public Secondary Schools in Ohaukwu LGA of Ebonyi State. GNOSI: An Interdisciplinary Journal of Human Theory and Praxis, 1(1), 34-40. 
Agbii, S. U., Chukwu, C. E., \& Iwundu, N. (2019). Enhancing Human Capital Development through Higher Education. GNOSI: $A n$ Interdisciplinary Journal of Human Theory and Praxis, 2(1), 48-55.

Ajeyalemi, D. (2008). The Issues of Quality and Quantity in Nigeria's Teacher Education System. Lagos: University of Lagos Press, 2008.

Aminu, J. (2008). Quality and Stress in Nigerian Education. Madiuguri \& Zaria: University of Maiduguri and Northern Nigeria Publishing Company, 1986.

Asouzu, I. (1990). "Progress in Metaphysics: The Phenomenon of Missing Link and Interdisciplinary Communication". Calabar Journal of Liberal Studies, 2.2 (1990): 8291.

Asouzu, I. (2007). Ibuanyidanda: New Complementary Ontology Beyond World-Immanetism, Ethnocentric Reduction and Impositions. Zweigniederlassung Zurich: Litverlag GmBh \& Co. KGWien, 2007.

Bisong, P (2018). Revisiting the Quality versus Quantity Debate in the context of Contemporary Educational System. Modern Research Studies. 5 (4), 206 -225.

Bisong, P. B., \& Ekanem, S. A. (2019). A Critique of Existentialist Philosophy of Education: Towards a formation of a balance Philosophy of Education for the African Continent. International Journal of Law, Management and Social Science, 3, 20-27.

Bisong, P. B., \& Ekanem, S. A. (2020). The Impact of Culture on Education in Africa: A Resolution from the Aristotelian Perspective. RAIS Journal for Social Sciences, 4(1), 57 67.

Bisong, P., \& Tawor, P. (2015). Human right violation conundrum: Asouzu's ibuanyidanda ontology as a remedy. Advances in Social
Sciences Research Journal. Vol, 2, 915.

Dennis, 0. (2020). Ethics of Posterity for Environmental Development of the Niger Delta.GNOSI: An Interdisciplinary Journal of Human Theory and Praxis, 3(3), 83-96.

Fafunwa, A. B. (1974). History of Education in Nigeria. London: George Allen \& Unwin.

Fafunwa, B. (1982). "African Education in Perspective". Education in Africa: A Comparative Survey. Ed. A. B. Fafunwa \& J.U. Aisiku. London: George \& Allen, 1982.

Feyerabend, P. (1975). "Against Method: Outline of an Anarchistic Theory of Knowledge." London: Atlantic Highlands: Humanities Press, 1975.

Feyerabend, P. (2015) "Science and Myth". http://www.inf.fuberlin.de/lehre/pmo/eng/Feyera bend-ScienceMyth.pdf. Retrieved March 22

Feyerabend, P. (2015). "Science: The Myth and its role in the Society". http://web.mit.edu/sdmorr/Publi c/STS/feyerabend.pdf. Retrieved March 22, 2015

Hamzah, F., Awaluddin, M., Siraj, M. L., \& Dos Santos, H. A. (2020). The Effect of Individual Characteristics on the Performance of Primary School Teachers in Bone District, Bone Regency of South Sulawesi, Indonesia. GNOSI: $\quad A n$ Interdisciplinary Journal of Human Theory and Praxis, 3(3), 49-66. 